Research Article

\title{
On the Road to Inclusive Education: Supporting Diversity in Education by State-Financed, Large-Scale OER Platforms-The Example of User-Oriented Development of NDLA in Norway
}

\author{
Frank J. Müller \\ University of Bremen, Faculty of Education, Bibliotheksstr.1, Bremen 28359, Germany \\ Correspondence should be addressed to Frank J. Müller; frankj.mueller@uni-bremen.de
}

Received 4 February 2021; Revised 31 May 2021; Accepted 3 June 2021; Published 14 June 2021

Academic Editor: Ehsan Namaziandost

Copyright @ 2021 Frank J. Müller. This is an open access article distributed under the Creative Commons Attribution License, which permits unrestricted use, distribution, and reproduction in any medium, provided the original work is properly cited.

\begin{abstract}
Inclusive education and the associated consideration of the diverse needs of students from different social, economic, and cultural backgrounds and different talents and disabilities are a worldwide challenge. This article shows how by addressing different user groups, state-funded platforms for open educational resources (OER) can contribute to the implementation of inclusive education. This is done using the example of the Norwegian platform NDLA, which has been providing open educational resources for upper secondary education in Norway since 2006. This paper is based on 13 expert interviews conducted with NDLA staff, cooperation partners, and members of the opposing schoolbook publishers union in 2017. The presented results focus on the diversity of learners, teachers, and platform staff and how this diversity is addressed. The presented results focus on the diversity of learners, teachers, and platform staff and how this diversity is addressed to ensure the best possible outcomes in learning and teaching. Finally, country-specific aspects that can be addressed by an OER platform are highlighted. In summary, the transferability of the Norwegian experience to other countries is discussed.
\end{abstract}

\section{Introduction}

The development of an inclusive education system for all learners is prominently anchored at the international level as an objective of the Sustainable Development Goals (SDG) by the United Nations [1] and in article 24 of the Convention on the Rights of Persons with Disabilities (CPRD) of the United Nations [2].

This article is based on an understanding of inclusion as described by Susan Peters in reference to the Salamanca Declaration:

(1) "All students come to school with diverse needs and abilities, so no students are fundamentally different.

(2) It is the responsibility of the general education system to be responsive to all students.

(3) A responsive general education system provides high expectations and standards, quality academic curriculum and instruction that are flexible and relevant, an accessible environment, and teachers who are well prepared to address the educational needs of all students.

(4) Progress in general education is a process evidenced by schools and communities working together to create citizens for an inclusive society who are educated to enjoy the full benefits, rights, and experiences of societal life." In [3] (Peters, 2007, p. 99), a broader concept of inclusion that includes other dimensions of heterogeneity in addition to disability is also advocated by [4] (Hinz, 2002) or in the South African white paper [5] (Department of Education, 2001)."

Inclusive education is therefore understood as a pedagogical approach that aims to go beyond the dimension of dis/ability to support all learners to develop their full potentials in social interaction and cooperation addressing structural disadvantages based on gender, sexual orientation, dis/ability, class, economic, social and cultural background (including indigenous people), race, languages, 
health, age, pregnancy and maternity, belief, and religion (or lack thereof).

Accordingly, the central question for many countries and school authorities is, how can we support teachers in establishing an inclusive education system and doing justice to the heterogeneity of their students?

One possible approach would be to provide Open Educational Resources (OER) that take diversity into account from the onset and, like Zhang [6] suggested, can be adapted by teachers to the needs of their students due to the different copyright model and that can subsequently be disseminated further for the use by other teachers.

In line with UNESCO [7] (2019, p. 5), Open Educational Resources are understood as follows:

(1) Open Educational Resources (OER) are learning, teaching, and research materials in any format and medium that reside in the public domain or are under copyright that have been released under an open license that permit no-cost access, re-use, repurpose, adaptation and redistribution by others.

(2) Open license refers to a license that respects the intellectual property rights of the copyright owner and provides permissions granting the public the rights to access, re-use, re-purpose, adapt, and redistribute educational materials.

(3) Information and communications technology (ICT) provide great potential for effective, equitable, and inclusive access to OER and their use, adaptation, and redistribution. They can open possibilities for OER to be accessible anytime and anywhere for everyone, including individuals with disabilities and individuals coming from marginalized or disadvantaged groups. They can help meet the needs of individual learners and effectively promote gender equality and incentivize innovative pedagogical, didactical and methodological approaches [7]."

Supporting diversity in education through ICT is not only about developing accessible resources, but also about systematically taking into account the diversity of learners and teachers while doing so.

To date, there has been no extensive research on how to utilize the great potential of OER for marginalized and disadvantaged groups, what the prerequisites are for doing so, and, in particular, to what extent existing OER platforms are already exploiting it.

Some country-specific OER platforms for schools have been developed, such as Wikiwijs in the Netherlands [8] or KlasCement in Belgium with an approach relying heavily on sharing materials [9]. The Norwegian OER Platform Nasjonal digital læringsarena (English title: Norwegian Digital Learning Arena, NDLA) has been gathering experience with a large-scale OER model since 2006. NDLA placed an emphasis on incorporating the needs of users in the design of materials and the platform. NDLA has often been discussed in the OER community as an example of what a governmental OER funding could look like, based on conference contributions from Norwegian colleagues. Simultaneously, it mostly remained a vague description of extensive state funding, being $20 \%$ of the textbook budget. The number of English language publications on the Norwegian model is very manageable and most of them contain rather brief mentions [10-12]. In 2019, the overarching findings in the study by Müller [13] were able to provide an insight into the broad experience of the Norwegian colleagues.

This article focuses in detail on how the team from NDLA deals with diversity in relation to the different user groups. The terminology is based on the approach of Design Thinking, like described by Brown [14] and others [15, 16], a set of methods aiming at problem-solving that places user needs at the center of a creative development process for new products, applications, or services. As will be shown, the users of the OER and the platform in this case are not only the students or the teachers.

In contrast to tools for school development processes such as the Index for Inclusion [17], which are aimed at the individual school level, in the Norwegian example, material is developed and made available at the county level. Every individual teacher (and also each student) can thus use the materials independently of school development processes. An appealing content and visual design of the materials in order to be attractive for as many teachers and students as possible are therefore an important prerequisite to be used in schools.

1.1. Research Questions. One of the overarching questions for the research project was, "What contributions can Open Educational Resources make to supporting teachers in dealing with diversity?" So far, there have been no studies on the handling of diversity on the part of governmental OER platforms. The background to this is also the small number of large-scale platforms.

The interviewees made clear that the diversity-related statements do not only refer to the teachers' handling of the diversity of the students but also include other areas of heterogeneity. The interviews provide an opportunity to explore to what extent and in what ways UNESCO's ideas are already being implemented in a state large-scale, statefunded OER platform.

For this article, the following questions will be analyzed in more depth:

(1) What role does dealing with diversity play for NDLA employees and cooperation partners?

(2) On which level is this diversity located, which dimensions of diversity are included, and to what extent is it consciously handled?

\section{Materials and Methods}

To learn more about the NDLA's approach, a series of on-site interviews were conducted in Norway in March 2017 in English. Nine NDLA management level staff members, three cooperation partners, and a representative of schoolbook publishers were interviewed. 
These interviews were conducted on the basis of a broad guideline covering several topics. The guideline was provided to the interview participants in advance. The questions were selected based on the expertise of the interviewee. Dealing with diversity has been a recurring focus of the interviews against the background of the professional biography as a teacher and professor of inclusive education. The transcription of the full interviews was carried out according to Müller [13]. Based on Mayring's concept of qualitative content analysis [18], a category system was developed using all interview texts. Thereby, according to the guideline of the interviews, top categories were created deductively and subcategories were developed inductively. These categories developed in this way were then applied again to all available material using MaxQDA 2018. The interviews were numbered, so that when quoting, reference was made to the respective number (e.g., [I8, 7-9] means interview 8 and paragraphs 7 to 9$)$.

\section{Results and Discussion}

The analysis of the statements that deal with the topic of diversity shows that these can be divided on the basis of the people on whom the statements are focused (see Figure 1). The direct users of the platform can be identified as the students, the teachers, and the NDLA staff. In addition, the political leaders as stakeholders are also defining requirements and at the same time represent diverse interests. In addition to the needs of the diverse users of the platforms, the representation of diversity in the content of OER is also addressed.

3.1. Diversity of Students. The statements on dealing with diversity on the student side can be divided into three areas: the way NDLA addresses students, the opportunities for teachers to make further adjustments, and the scope for students to deviate from the paths offered.

3.1.1. NDLA Addressing the Students Diversity. Since pupils are the main users of the platform, their needs should be central to the development of OER. This statement seems to be obvious but was simultaneously a development process on the part of NDLA to come to this shift in focus from the teachers needs to the students' needs:

The biggest change we done is... I think it was healthy for NDLA the first years to be focused on the teachers until it became all of a movement. But it's not possible for us anymore to speak about the pupils, we had to speak to the pupils and with the pupils. And not only them but to, kind of conceptionally, we need to be focused on learning. So NDLA's business is learning. And is not one pupil, it's the three pupils working together, getting advice from the teacher, gathering some information from other parents, which have special competences within one area and so on [I3 7-7].

To focus on the students and their diversity, NDLA uses an approach from Design Thinking, as described by Chen and Liu [19]. Using the so-called personas (fictitious pupils or teachers described in detail) helps the editors not to lose sight of and to understand the diversity of the students in the creation of OER. The personas describe favorite subjects, interests, learning situations, life situations, and digital competences of female and male learners and teachers as vividly as possible.

He is a student at, lets say, math, higher math and physics. How would he react? To force us to actually think about real students and real people and have that with us all the time when we produce stuff. Because it's so easy to think of them just as a group and there is such a variety and we need to focus on all kind of things that are important. It's not just that we have students who are functioning well but we have students with all kinds of problems, it might be visual, hearing. To think about these things as well, concentration issues, just anything. Of course we can't just create 200.000 personas, with all the students that we have in Norway, but some, some typical, some bigger groups. I think that has helped us in our work as well [I11 27-27].

In addition to the dimensions considered so far (gender, vocational/academic), new personas are currently being developed to better reflect diversity.

I: What dimensions of diversity, would you say, matter most in those personas? Is it gender? Is it disability and different kinds of impairment or is it different levels of achievement or can you name some dimensions of diversity, that matter the most?

A: At least we focus on gender for one and than we focus on vocational versus academicals so we have three of each. I am working on some new now, because we didn't have them all. We have the difference between the students who are really the topnotch, who want to become lawyers and some of them struggle with how much should I read, how can I really achieve those top grades. The really weak, the students who struggle, because they haven't in middle school or in even primary school, they haven't gotten the basics of math or Norwegian. They sort of take their problems with them through the system, so that's a difference. Also Norwegian/ Non-Norwegian, like saying you are from Syria or another country, who have actually traveled and struggle with, I mean some of them struggle with the language and everything. Others can be really smart in math or in English and that kind of stuff. Some of the Norwegian subjects, such as trying to learn religion or any other subject in Norwegian is difficult because of all the words that they don't know. That's another dimension. Then being practical and more theoretical. Also we need to have some underachievers, because there are some of them as well who only go to school, like a lot of students: how little can I do to get good grades, sort of. I think those are some of the dimensions 


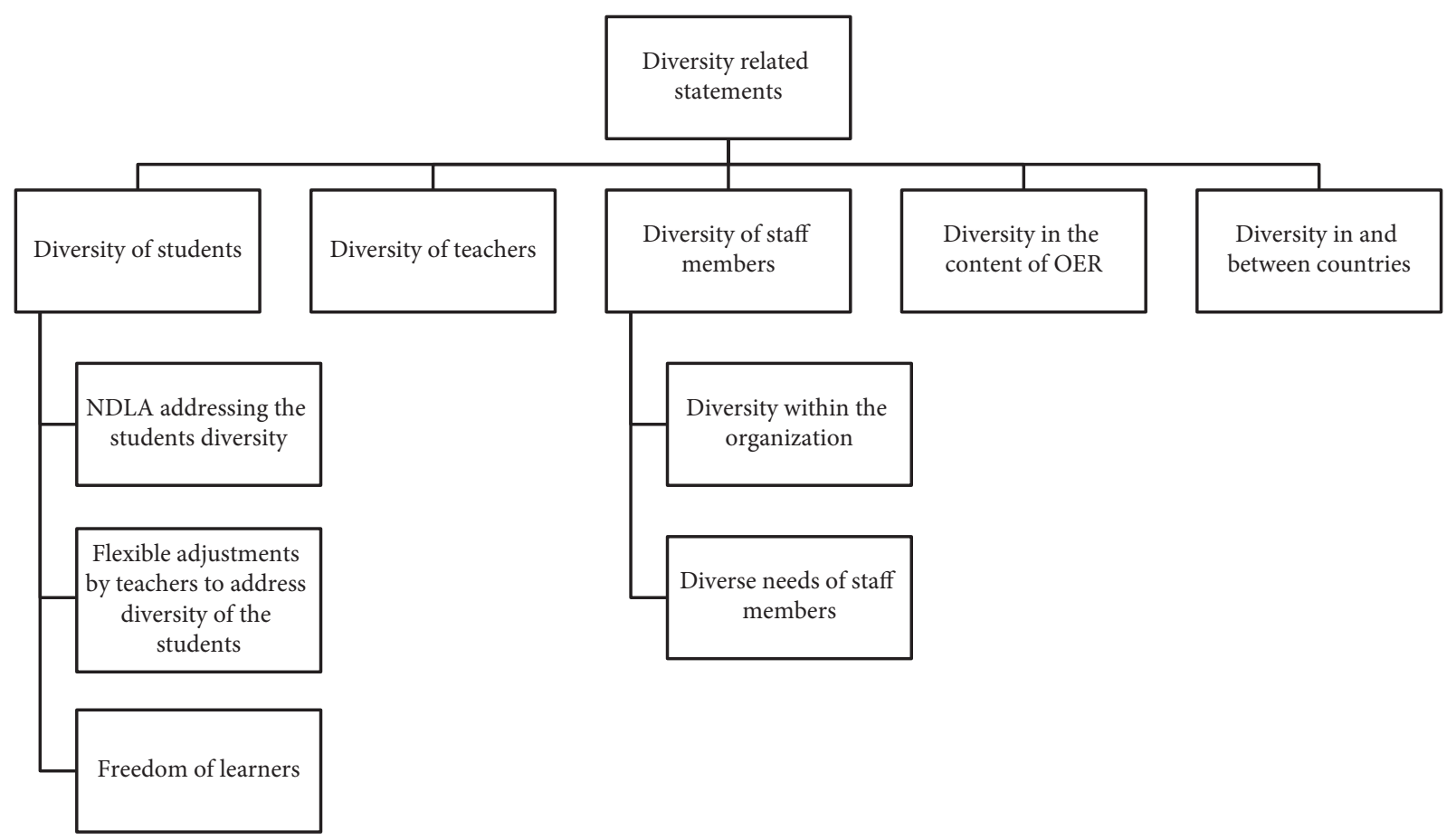

Figure 1: Diversity-related statements from members and cooperation partners of NDLA.

anyway. And of course age. That's what we call version one. We need to work on more as well, to add more to it. We started there and that was ... yeah [I11 28-29].

The personas used by NDLA are freely available on the usability platform (https://brukskvalitetsplattform.ndla.no/ personas.html) and are also accessible to non-Norwegian speaking readers via Google Translate.

The development of the personas has also been made possible by working with cooperating "pilot schools" [I1 23-23] where observations and testing of student usage behaviour have been made possible. This form of involving real end users in the development process of new material is in the spirit of design thinking and allows diversity to be taken into account and new barriers to be avoided [I11 5153].

In order to make materials as accessible as possible, the standards for accessibility, like WCAG 2.1 by W3C [20], are also used. This was a painful process for the NDLA team, as this was only done at a later stage and all existing videos will have to be subtitled until 2021 [I4 12-15]. New platforms should therefore be advised to observe these standards from the beginning in order to avoid later time-consuming and expensive rework.

In addition to these obvious requirements imposed by the accessibility guidelines, there are other major challenges that have become clear in the observations made at the "pilot schools." These include, in particular, pupils with reading difficulties, as has been noticed in analyses.

A: This standard tell us technically how we should present the content, we know that this will not be enough. We know from our last test that when we test some of the user interfaces some of our content today we have a right column, in much of the content we have. You know that eight out of nine pupils would not even look at the content in the right column. They will not look at it. And we know: because we eye-tracked it. The ninth pupil first looked at the right column and used a lot of time there before looking at something else. He was diagnosed with reading and writing disabilities. So we have to bring this issue up on a higher level. It will not help you putting a handicaptoilet on the top of the stairs. Even if it's perfect for solving the problems but the stairs will prevent them to getting up there probably. And that's the way we also with the digital user interface. So to us, and especially within 2018, 2021 we have to have all other content all producers in history also, available within the "WCAG standard." But the issues is [sic] much bigger for us so we do not have any other questions we have a lot of focus on it and we will have more and more focus on it during the next years [I3 61-61].

In response to this, NDLA is increasingly offering audio, video, and multimedia content as a supplement or alternative to text-heavy material [I11 51-51].

The consideration of the pupils has an effect not only on the form of the offers but also on the contents as NDLA tries to establish references to their diverse lifeworld [I11 3-3] and interests in the materials [I12 25-25].

NDLA is also relevant outside of school as a self-learning resource. NDLA reflects the different needs of students depending on the time of day, the stage of learning, and the place where students are physically located (in school, on the bus, and at home). The diversity of students thus also includes intrapersonal differences in needs. 
But we know that when a pupil has been reading on preparing for exams for three days and has been sitting ten hours today preparing for those exams, then we know that when she is going to start at seven PM in the evening, start to prepare for small glossary test tomorrow, then we know she is not really interested in reading more. Then we know she needs something to listen to or something like a video or something else. So, it is not only about strategy so how pupil best consumes learning for her personality it's situation based. When I'm here in the bus I do not want to read page by page of text. I want to put on my headset and see a introduction video. So it's not only learning strategy, it's situational learning [I3 51-51].

Another way of looking at the diversity of the students is the access via Big Data, which can show which materials are being used successfully and which need to be improved. However, not having to log in and not collecting sensitive data makes it more difficult to analyze this in relation to individual student characteristics.

Simultaneously there is also a sensitization regarding possible attributions by algorithms that may categorize students and offer them only one-sided learning opportunities.

But there's also some sort of Pandora's box here. If you have a 10-12 year old student in 10-15 years time.... At some point of time it sort of takes a test. And they find out, you're not very textual, you're a more visual type... you do not like this, you do not like this, you do not like this.., so now we're going to streamline something for you.

There's sort of horrible thought when it comes to individual freedom and the fact that we change and we... I mean, if you do not like reading texts... you're a visual guy, does that mean, that we should feed that feature in you all the time? Or should not you be exposed to a lot of text? So it is, when you talk about customization... it's a very fine line between sort of predicting, that you're not going to be a new Einstein, so we're going to feed you with simple tasks. And you're 12 years-old and in two years you have developed extremely, and perhaps, it will become Einstein...So, that's the really scary part about customizing, about sort of. . you said, "it'll be too much, yeah we'll customize it for you." But how to make sure, that that process will enrich your life and not limit it? That's a huge question.

Most of the Norwegian literary stars, like Ibsen and Bjørnson, they would probably have been on medication or had some kind of counselling. Weird types, autists [I12 88-90].

A central objective of NDLA, which is also linked to dealing with diversity, is to teach students how to work with other students (with different skills and needs) and not just to work quietly on digital tasks.

Anyway because I think if you read that paper [the pedagogical platform of NDLA] you will see that we are telling the teachers that if you're going to use a computer in your lessons, you have to let the pupils be active. You have to let them work, you have to let them cooperate and so on. If you let them hide behind a screen and do the teaching from above, then they will soon be on Facebook. And I do not mind pupils being on Facebook. I think when Facebook is an issue let's use Facebook to create good teaching or good learning [I5 82-82].

To deal with subject matter and classmates in such a way requires space and structure.

3.1.2. Flexible Adjustments by Teachers to Address Diversity of the Students. Offering this space and structure is the task of the respective teacher. NDLA provides an instrument for this with the new, specially developed software: the learning paths [I5 39-43]. They allow a contextualization of information and a structured, individualized offer for single groups of students. Thus, based on the needs and interests of the students, adapted paths through the content can be made available. These can be worked on by the students independently in a team. This way, the difficulty levels are assigned by the teachers so that negative attributions (level 1 student versus level 3 student) can be avoided [I 13 66-68]. These learning paths can be easily shared with other teachers, similar to a Spotify (or the like) playlist.

3.1.3. Freedom of Learners. The collaborative work of the pupils should be able to leave the digital space in order to achieve a higher degree of vividness or relevance for everyday life [I11 49-49]. Teachers should integrate such opportunities to create creative spaces (e.g., developing their own game) [I6 139-139] into the learning paths. The interviewees also emphasized the need to offer learners the freedom to deviate from these learning paths or to leave them completely [I13 91-95].

A central argument for OERs from an inclusive perspective is the adaptability of content to the needs of learners by teachers [3]. If there cannot be "one material to rule them all," then it is all the more necessary that teachers can make adaptations and in turn legally share the revised material with others. This refers to providing different ways of accessing materials as well as embedding them in local contexts that allow for lifeworld relevance.

In summary, NDLA already takes the diversity of pupils into account in many respects and also strives to broaden its perspective. Due to the legal requirements for accessibility, these aspects such as subtitles and alternative texts for images have come more into focus. However, especially pupils with cognitive impairments and learning difficulties have not been given much consideration so far. The involvement of inclusive schools that teach such pupils as pilot schools would be helpful here.

3.2. Diversity of Teachers. Diversity in schools also includes the teaching staff. As gatekeepers, they are responsible for the content and form of the lessons. Their own ideas, 
priorities, beliefs about teaching, didactic concepts, and the perception of the students' needs shape the lessons they design. This applies equally to the use of digital media. Here, too, a broad spectrum of motivation and competence can be found (as with the students) [I5 143-146].

On a professional level, this can be described with the TPACK model by Koehler and Mishra [21]. The diversity of the teachers is not limited to this but also includes personal experiences due to their positioning in a variety of dimensions (gender, dis/ability, sexual orientation, mother tongue, cultural and socioeconomic background, urban/ rural schools, and the resulting attributions as well as appreciation, devaluation, and exclusion), which have an influence on the teachers' decisions regarding the design of the lessons.

Offers designed to support teachers must take this diversity into account. NDLA has recognized this and has also constructed personas for teachers to serve as orientation for content developers [I11 27-27]. So far, the focus has been on the different digital affinities.

Simultaneously, NDLA feels obliged to an educational openness towards didactic approaches [I5 81-82]. Even if individual employees prefer certain pedagogical concepts, the content is constructed in such a way that it can be used with different didactic approaches and no recommendations are made until their success can be clearly empirically proven [I3 52-53].

In Norway, too, there are teachers who are more or less successful in their profession. However, NDLA staff remain realistic about the influence of digital media and OER on the teaching quality.

I think, in many schools, that the individual need for learning is so different and there is an expectation from the parents and an expectation from the pupils that we shall meet this individual and perhaps the digital resources can help us in that direction as well. I do not know, but I do not think that bad teaching can be better on computer, I do not think that. I think it's the substance in the teachers, organizing in the classroom, and if you use the computer or the book, that will not be the big questions, it's how it's creating good learning sessions for the pupils [I9 69-69].

This quote emphasizes the importance of the interplay of technological, pedagogical, and content-related skills, as described in the TPACK model [16]. Nevertheless, it might be worth considering whether meta information like didactic comments or exemplary application scenarios linked to the OER might not strengthen the reflected use of the materials and thus contribute to the further development of the individual teacher's teaching.

As illustrated, diversity on the part of teachers encompasses more than differences in digital literacy and the didactic approaches used. However, NDLA strives to be sensitive to these differences and to reach as many teachers as possible.

In conclusion, the involvement of teachers and students in the creation and revision of materials offers great opportunities to contribute to the representation of different perspectives within the OER and to the dissemination of the materials in their respective communities. Possibilities for involving teachers from different backgrounds are shown in the following section.

3.3. Diversity of Staff Members. The diversity related statements on the level of NDLA's staff refer to the diversity of the staff, the adjustments of the new platform to meet the needs of the staff, and the diversity awareness with regard to the content of OER.

3.3.1. Diversity within the Organization. The diversity within NDLA's staff is not very high, especially in terms of cultural diversity, but there is an awareness of the problem.

A: You know, as Germany Norway is a multi-cultural nation. I think we have to be better, but we are struggling to, for example, to use a picture to think this people have different cultural background, how can we use it in our creative way, in the way we address them? But it's not so easy, because everyone working in NDLA are white, Norwegian people, so we have not that background ourselves and I think it's different. We're trying and we are using text from other places in the world so that literary texts and we are trying to when we are using a picture or students working in the classroom, there should be someone with a hijab and someone who's black, you know. And so they can see that this is the normality in Norway, this is like Norway is now. But I think because we have not that background ourselves it's not so easy to do it right. So I think this is something we have to work with [I13 70-70].

Sometimes, large age differences between staff and students are also addressed, because in some cases the personal connection to the rapidly developing lifestyles of the young people is lost [I13 74-74].

The issue of lacking gender equality at NDLA is a question that seems to be particularly relevant for the management level.

I: Yeah, so how is it with gender? You already mentioned the white male Wikipedia-guys, is it in NDLA, is it equally distributed or is it more on the content-producer-side? Is it women and men equally or is it more men or? Or more women?

A: Yeah, it's an interesting question. When we start back in I think this was quite equal. At this time, the top leaders in NDLA is men and the work is on the lowest levels almost everyone a woman, so I addressed this. Not everyone liked it, but at least some did (laughter). It's a danger. OK, it's like the rest of the society when you get to the leaders, there is more men and that should not be like that so this I'm telling this young men, Øivind and Pål, so I say "You have to choose not the people that are like you, you have to choose some other" but that's a problem for all of us. So, I think we have to be aware of this. I'm so old 
that I see there are not so many years before I will be in pension, but I will strongly tell them that (laughter) this is really important [I13 71-72].

All in all, the question of how people with different genders as well as social, cultural, and economic backgrounds can be represented in an organization like NDLA at all and across all levels seems to be a challenge that should be systematically tackled if it is to be successfully addressed.

One possible way to include more perspectives in the creation of new materials is to convene all stakeholders to develop materials for a subject at the beginning of the process.

Our success the 3-4 last years has been to invite all parties with interest in communicating knowledge within a subject to the society to workshops and to collaborate on building this. We did this on the history subject (history one and two), we started that with religion now and a sociology-similar subject. We will probably follow that origin that means network production, conceptually quite similar to what Alexander Osterwalder did when he build the business model generation book. He was the moderator of 450 editors [I3 49-49].

The democratization of the means of production (highperformance computers and video cameras in everyone's pocket) is making a significant change possible in terms of the involvement of teachers and students in the development of materials [I 12 87-87]. Particularly, against the background of the diversity described above, an approach that would involve more people in development would be appropriate here. Experience with Wikipedia has shown that the voluntary, low-threshold participation opportunities there lead to uneven participation across the various heterogeneity dimensions and that traditional power structures are perpetuated, as described by Lam et al. [22] and Wagner et al. [23, 24]. The question therefore arises for OER platforms as to who can be motivated to participate and in what way. Which social circumstances may lead to non-participation of individual groups? How can these groups be included? One way that is used in Norway is to pay the contributors.

A: Yeah, we talk a lot about this with Christer, he is spokesman for this Wikipedia creating things. I'm not so sure it will function, because Norway is a very small country, really the number of teachers is not so very high. Most of the teachers they have a very busy day, they have no time for this, there are some, and it's always the same people and they are always men, you know (laughter). Perhaps the best quality are the woman teachers, they are doing it very far. But they have a very busy day with family and everything and when we are giving them "Ok, two days a week we are paying you!" and then you can have a job for this quarter and next and they have this two day, they can work for NDLA for a period for a year. Or some, when we are going to get smaller, we are paying them until 30,000 Norwegian Crowns, then they take it on top of the job, but they get paid and then they, I think this is also a way of feeling you are delivering quality, someone is paying you and I think the best things we get are when people get some day off to work with it and can do it really serious and they are proud of what they're doing and they got response from us and they are feeling safe and I will prefer this way working, you know [I13 56-56].

Other ways of recognition with a high motivational character for teachers are also imaginable, for example, including the created OER in official assessments or flexible free days off.

Support services are also used to help teachers with less digital affinity to develop materials. For example, they do not have to deal with the procurement and licensing of image material or search engine optimization but can concentrate on content and didactic design [I 4 6-6]. These support structures enable a wider range of colleagues involved. At the same time, there is still potential to develop a low-threshold participation [I12 72-73].

Digitization has also made it possible for teachers living in rural areas to contribute their skills and perspectives to the development of OER. NDLA has promoted this in particular through regional workshops, which contribute to crossschool networking of subject colleagues and provide an introduction to the world of OER [I13 56-56].

3.3.2. Diverse Needs of Staff Members. An Internet offer should, in the interest of its own success, always try to consider the needs of the end users (here students and teachers). However, the needs of the editors and other staff members are also important, especially on large platforms. The development of NDLA on the basis of a content management system (Drupal), which was not designed for use as a learning platform, led to the fact that the wishes of the editors were realized by means of more and more new plug-ins, making the system sluggish, unstable, and difficult to maintain.

The needs of employees refer both to the backend, where the materials are created, and to the frontend, where they are presented to the learners. The development of a new platform, specifically designed for the dissemination of OER (and not just a content management system), has made it possible to systematically take into account the needs of team members from the very beginning and to simplify and accelerate the process of creating materials. This also includes being able to divide the processes according to the strengths of the team members. This means that, for example, (seconded) teachers do not have to deal with image searches or, if they do, that the input masks work with terms that teachers can understand [112 75-82].

The different needs of the employees result from their perspectives on their subject (requirements for the frontend) and their role in the team (requirements for the backend).

Regarding the perspectives on the subject and the requirements on the frontend, the interviews emphasized the importance of putting the real end users in the center of development. Many teachers and material developers with 
many years of experience believe they know what is right and good for students. This belief had to be shaken.

A: We have people who has been working on traditional learning resource development, modelers, for the past 20 years. And they are kind of setting that way of thinking. So the teachers know the pupils, they know better then the pupils how things should be presented and what they should learn. They know their experience, they know so much about pupils so they can just tell them what to do, and then they will learn and so on. We have to challenge that kind of culture. Best way we experience to do it is that "okay, let them makes some resources" and then we out them into a user-interface and then we send them out to the pupils together with professional pupil doing user-testing. Eyetracking and everything. Not only communicating with them but also observing and observing professionally. Just let them observe, what happens? And if they observe there, they will also have, for the first, two, three, four times, an enormous amount of competency increase in the area of how valuable is that pupil, every time. They get so surprised and there are small things they did not think about, which just makes the pupil leave the resource. And then you can be right as much as you like but as long as the pupil does not want to open that page then it can be right there but you will not read to people. So that is one of the things we have to work on step by step [I3 9-9].

Simultaneously it should be noted that the consideration of the needs of the employees for the backend is an important prerequisite for the efficient operation of a largescale platform [I12 153-154]. This is addressed by a rolebased editor with an efficient design of input mask and processes [I12 158-160]. In addition to the technical and process level, this also includes the cleanest possible documentation of standards and expectations to which (new) employees should orient themselves. NDLA achieves this through various documents: the pedagogical platform, the usability manual (https://brukskvalitetsplattform.ndla.no/), and the design manual (https://designmanual.ndla.no/).

3.4. Diversity Awareness with regard to the Content of OER. An example of a form of awareness that has been achieved by anchoring it in legislation is the sensitivity to gender issues at NDLA, which goes back to the state auditing of textbooks. Gender issues in OER are therefore addressed through a combination of awareness and user feedback at NDLA.

\section{I: Do you think about gender, for example?}

A: Of course, that's a very important thing in Norway, I've been writing textbooks for the upper secondary school for about 20 years and that, the gender part, was one point in which the government was looking into to accept the books to be used, but that acceptance was dropped in 2001, so now you can use any stuff in the school, but before that there was a stamp you had that said: "This book is approved by the government to be used and the gender part you had to cover both sides and discuss it, that was important thing, so I think that as well is very much in the minds of the people.

I: It's already in the mind, so you do not have to check box for it?

A: No, we do not do that, if we do a wrong step or do anything wrong there, there would be people writing to us and say: "Hey, that's not right!" [I5 46-51].

The aim today is to include female perspectives in the materials and not to treat them separately in an extra paragraph about women in the era. A similar process could be developed for people with disabilities, different cultural backgrounds, and sexual orientation.

3.5. Diversity in and between Countries. Requirements at the state level are defined by political representatives and by employees of the educational administration. As stakeholders, they are another group that influences the design of a platform and its content. This can be directly through participation in decision-making bodies (Board of Directors) or indirectly, for example, through the design of curricula. Since the continued existence of such a platform is always also a political decision, the consideration of these interests is important as well.

The requirements within a country are also heterogeneous. This is especially related to the differences in the students' lifeworld, which the platform tries to take up. The inclusion of local content (be it geographical, historical, ecological, political, or cultural) is a particular potential of OER. This can be attributed to several factors: the available space in digital space (compared to a textbook with a limited number of pages), the involvement of locally rooted teachers, and other interested parties (local museums, archives, universities) in the creation of content and the lack of pressure for economic viability.

But that was like what I was saying about the local thing because in, I was telling you about the toll lists [see below FJM], and they actually have, in Bergen in 1736 there were four cages for canary birds that where imported to Bergen. And for a person today living in Bergen to know that it's like a total different way of perspective telling a story. History as a subject as well. So it gets more localized because I [as a commercial publisher FJM] have 2050 pages and I have to tell the world history. I can't use 20 pages like this to dive into the noble arts of canary birds in Bergen, I have enough with the main topics. So they have the possibility of making a richer subject where teachers can choose [I10 183-183].

Local references (including GPS data) allow students to leave the digital space and interact directly with their environment.

The inclusion of linguistic minorities is of particular importance with regard to the heterogeneity within a country. NDLA has therefore developed materials for the 
Sami language, regardless of how many pupils there are for the subject [I13 46-48]. The free accessibility also makes it possible for other people to use the materials for informal learning. There is enormous potential for other countries in this area. In Namibia, for example, there are 14 official languages, which are represented in varying degrees regionally and whose speakers would benefit enormously from the availability of interconnected multilingual materials [25]. This also applies to materials in the first languages of the pupils, which are not necessarily supported as protected minority languages, as defined, for example, by the Council of Europe [26] or official languages. In Germany this would be the case, for example, for Turkish, Arabic, Farsi, Slavic languages, and others, who are taught in various settings [27]. Materials to support first language acquisition with a link to the second language are especially important for elementary school, but also for older refugees.

In addition to local content and linguistic access, the multiperspectivity made possible by OER is a particular added value. This makes it possible to take up the perspectives of various actors who locate themselves on multiple dimensions (gender, sexual orientation, POC, dis/ ability, economic, cultural and social backgrounds, and urban versus rural), which have so far been poorly represented in textbooks. These interests are represented by civil society interest groups, museums, universities, and political actors. This involvement of third parties costs time and energy that commercial suppliers cannot invest in this form.

They now have 10 years of publishing and working in the educational field and they are getting pretty good at it. The stuff that I see that they make from the content that I have sold them is actually a lot better than the content that I sold them. So they make multimedia-rich, they developed a good skill set on making digital learning materials. I'm impressed actually. And they also do another thing. They have changed a little bit from their start because they have no turned into a sort of collaborative organization. So I'm working specifically with history as an subject, I published history books and so on. But what they did when they revived their history, was that they made connections with the statistical bureaus, museums all over Norway, people that work with historical toll lists to watch what kind of imports and exports that came out of Bergen in the seventeen hundreds. So it was not anymore an one-editor in a crew of "webbies" and some people that bought stuff. Now they say there is a lot of connections to other, to NGO's, government organizations, to museums, to any kind of organization that's sort of interested into the same thing that NDLA is, which is making a great history subject. So it's become a collaborative organization. And they do that in a way that is impossible for publishers to do. Because our work is to buy material and sell it. We will not be using 200 hours to make connections with people outside of the project that probably will not matter a lot. We would go directly to the ones that really need to save money on time. So, the collaborativeness; I love the idea, I think is fantastic. And they can do that because they are free the governmental. They do not need to make money, they can do that. And they go on and build sort of collaborative networks from partners that have the same objective. So that I think that it is a much more mature organization and that improves teaching aids enormously [I10 181-183].

Wherever possible, NDLA strives to keep the workload for cooperation partners as low as possible and to exchange data via interfaces (APIs) [I5 110-112].

By including different perspectives, it is possible to contribute to the development of empathy, which is especially important in times of increasingly divided societies. In addition to the consideration of diversity among students and teachers in order to facilitate access to learning content, diversity itself becomes learning content in order to promote tolerance, acceptance, and understanding in dealing with each other. Here, it will be challenging to also take into account the perspectives of those who have been privileged up to now in order to enable a real dialogue.

The diversity of content, not only focused on the question of multiperspectivity, is an issue of importance to NDLA employees, opponents, and cooperation partners. On the part of the textbook publishers, there is a fear that a too extensive offer by NDLA will limit the diversity of the other market-driven offers [I8 86-86]. At the same time, it should be noted that all respondents emphasized that it is in their interest that NDLA remains one of many offerings and that teachers should have a free choice [I8 11-11, I9 67-67, I10 1919]. There are also no efforts to increase NDLA's share beyond the $20 \%$ of the textbook budget. In addition, $70 \%$ of NDLA's budget is being put back on the market through public tenders [I1 20-20] so that $94 \%$ of the textbook budget is still available to the market.

\section{Conclusions}

The questions, "what role does dealing with diversity play for NDLA employees and cooperation partners?" and "on which level is this diversity located, which dimensions are included and to what extent is it consciously handled?," can now be answered on the basis of the Norwegian experience. According to the analyzed statements of the respondents, NDLA takes diversity into account at various levels. This includes, on the one hand, the user-oriented accessible design of platform and content for various user groups, but on the other hand the inclusion of diversity as a learning content.

The Norwegian example shows in particular the potential of user-oriented development of materials and the platform on which they are provided. Following the Norwegian approach and in alignment with the concept of Design Thinking, the needs of the users are placed in the center of the development. For user-centered design, the question, "who are the users?" is of particular importance. Users with relevant interests and needs are the students, teachers, platform staff, and cooperation partners. Additional stakeholders are policy makers and educational administrators. NDLA originally focused primarily on teachers 
but has expanded this focus to include students. The needs of the editors were also taken into account when revising the technological platform and developing the new software.

In order to involve the users, fictitious personas based on typical users, like described by Chen and Liu [19], are used in addition to observations and studies in pilot schools. These personas help editors to keep an eye on the diversity of students during the development process. There is certainly still room to expand these personas and to include further heterogeneity dimensions by using additional fictitious students. The dimension dis/ability is, for example, currently more influenced by the law requirements for accessibility and less by personas. In addition to the consideration of accessibility, the question of vividness would be of importance here, which focuses in particular on the concrete interaction with objects and may require leaving the digital space.

But even with a stronger focus on vividness, there will not be one material that is suitable for all students at the same time. However, further customization of content is the responsibility of the individual teacher, who must ensure that NDLA's materials are appropriate to the students' learning context. Thanks to the open license, there is the possibility of adapting the content. In addition, the teacher can offer individual paths for groups of students with the help of the new learning path feature.

When it comes to the question of how to successfully integrate diversity as a learning content, Norway can look back on extensive experience with the consideration of women, where legal regulations have led to a sensitization of developers and users. The comprehensive inclusion and reflection (as opposed to an additive presentation in separate paragraphs) is something that has not yet been achieved for other dimensions of heterogeneity.

To add further perspectives, the additional space available in digital formats compared to traditional textbooks is a necessary prerequisite. Simultaneously, it is essential to involve self-advocates in the process in order to make use of this space. NDLA has set out to include all interested parties on a topic from the very beginning via stakeholder conferences. In order not only to address technology-oriented people with time, it is necessary to consider which formats of involvement are best suited to bring in women, people with disabilities, POC, LGBTQi representatives, and linguistic and cultural minorities. Consequently, the increase in available space is also associated with higher costs for the production and maintenance of materials. At the same time, the additional perspectives enable a stronger identification with the material or support the development of empathy $[28,29]$, which both have been identified as factors of openness towards diversity [30].

Steiner-Khamsi [31] describes the problems of policy borrowing, in particular the projection of national interests onto "empty vessels" of policies, but also the spread of transnational corporations in the education market. Accordingly, it is not about the simple worldwide adoption of current strategies and concepts such as OER, but rather about the reflection on how relevant content can be made available for the respective target groups. Thanks to the $\mathrm{cc}$ licence, content and resources can be taken over from other countries, but they have to be adapted to the local contexts. Richter and
McPherson [32] describe in detail what this adaptation process can look like. Open documentation of the development process and the context as well as open, easily modifiable formats are of particular importance in order to facilitate adaptations. Methodological approaches such as working with personas and other aspects of design thinking must also be critically reviewed for culturally sensitive adaptation needs before use in other countries, as described by Callahan [33]. She suggests, for example, that in less individual-oriented countries, personas should be described in a more relationship-oriented way.

The inclusion of the perspectives of teachers, students, politicians, and developers on-site as stakeholders contributes to taking into account the local characteristics of different countries. In this way, it is possible to support the development of schools and the teaching of individual teachers and not to lose sight of the needs by simply adopting content and structures.

Based on a broad concept of inclusion that goes beyond the dimension of dis/ability, it was shown that the great potential of Open Educational Resources for equal, inclusive access to education for everyone stated by the UN [9] does not materialize by itself. However, the Norwegian example of NDLA shows that awareness of this challenge exists and includes solutions to achieve representation of diversity among both creators and users (teachers and students) and in the content of OER.

\section{Data Availability}

The data used to support the findings of this study are available from the corresponding author upon request.

\section{Disclosure}

The funding agencies had no influence on the outcomes of the research.

\section{Conflicts of Interest}

The author declares that he has no conflicts of interest.

\section{Acknowledgments}

The author thanks all interview partners who gladly gave insight into their broad experience with OER. A special thanks also goes to Leanne Lütjen for her contribution to the project and to David Benson for improving the manuscript. This project was funded by the University of Bremen, the Max-Traeger-Foundation, and the city of Bremerhaven.

\section{References}

[1] United Nations, The Sustainable Development Goals Report 2020, New York, NY, USA, 2020, https://unstats.un.org/sdgs/report/ 2020/The-Sustainable-Development-Goals-Report-2020.pdf.

[2] United Nations, Convention on the Rights of Persons with Disabilities, United Nations, New York, NY, USA, 2006, https:// www.un.org/development/desa/disabilities/convention-on-therights-of-persons-with-disabilities/convention-on-the-rightsof-persons-with-disabilities-2.html. 
[3] S. J. Peters, “"Education for all?” A historical analysis of international inclusive education policy and individuals with disabilities," Journal of Disability Policy Studies, vol. 18, no. 2, pp. 98-108, 2007.

[4] A. Hinz, "Von der Integration zur Inklusion-terminologisches Spiel oder konzeptionelle Weiterentwicklung," Zeitschrift für Heilpädagogik, vol. 53, no. 9, pp. 354-361, 2002.

[5] Department of Education, Education White Paper 6: Special Needs Education Building an Inclusive Education and Training System, Department of Education, London, UK, 2001, http:// www.info.gov.za/whitepapers/2001/educ6.pdf.

[6] X. Zhang, A. Tlili, F. Nascimbeni et al., "Accessibility within open educational resources and practices for disabled learners: a systematic literature review," Smart Learning Environments, vol. 7, no. 1, pp. 1-19, 2020.

[7] UNESCO, What Are Open Educational Resources (OERs)?, UNESCO, Paris, France, 2015, https://web.archive.org/web/ 20150413184825/http://www.unesco.org/new/en/ communication-and-information/access-to-knowledge/ open-educational-resources/what-are-open-educationalresources-oers/.

[8] R. Schuwer, K. Kreijns, and M. Vermeulen, "Wikiwijs: an unexpected journey and the lessons learned towards OER," Open Praxis, vol. 6, no. 2, pp. 91-102, 2014.

[9] B. Pynoo and J. Van Braak, "Predicting teachers' generative and receptive use of an educational portal by intention, attitude and self-reported use," Computers in Human Behavior, vol. 34, pp. 315-322, 2014.

[10] N. Abbas, From Paper to Digital, and Back. A Qualitative Study of the Publishing of Open Educational Resource Based Textbooks in a Knowledge Society, University of Oslo, Oslo, Norway, 2016, http://urn.nb.no/URN:NBN:no-55488.

[11] L. S. A. Johnson and C. Hall, 2015 NMC Technology Outlook for Scandinavian Schools, NMC, Rochelle, IL, USA, 2015, https://www.learntechlib.org/p/182056.

[12] J. M. Pawlowski, E. Ossiannilsson, A. Creelman et al., "The nordic alliance for open education-state of the art, challenges and opportunities," in Proceedings of the European Distance and E-Learning Network 2013 Annual Conference, Oslo, Norway, June, 2013, http://lup.lub.lu.se/record/3917567/file/ 3917577.pdf.

[13] F. J. Müller, Opportunities and Challenges of State-Financed Open Educational Resources: The Norwegian Model-A Way to More Inclusion?, https://osf.io/preprints/socarxiv/7325g/, Verlag ZLL21 e.V, Hamburg, Germany, 2019, https://osf.io/ preprints/socarxiv/7325g/.

[14] T. Brown, Change by Design: How Design Thinking Transforms Organizations and Inspires Innovation, Harper Business, New York, NY, USA, 2009.

[15] M. G. Luchs, K. Scott Swan, and A. Griffin, "Design thinking: new product development essentials from the PDMA," in Design Thinking: New Product Development Essentials from the PDMA, pp. 1-431, Wiley, Hoboken, NJ, USA, 2015.

[16] R. M. Müller and K. Thoring, "Design thinking vs. Lean startup: a comparison of two user-driven innovation strategies," in Proceedings of the 2012 International Design Management Research Conference, pp. 151-161, Boston, MA, USA, 2012.

[17] T. Booth and M. Ainscow, Index for Inclusion: Developing Learning and Participation in Schools, Centre for Studies on Inclusive Education, Bristol, UK, 2011.
[18] P. Mayring, "Qualitative content analysis," Forum Qualitative Sozialforschung/Forum: Qualitative Social Research, vol. 1, no. 2, 2000.

[19] R. Chen and J. Liu, "Personas: powerful tool for designers," in Design Thinking, pp. 27-40, John Wiley \& Sons, Hoboken, NJ, USA, 2015.

[20] W3C, "Web content accessibility guidelines (WCAG) 2.1," 2018, https://www.w3.org/TR/WCAG21/.

[21] M. Koehler and P. Mishra, "What is technological pedagogical content knowledge (TPACK)?" Contemporary Issues in Technology and Teacher Education, vol. 9, no. 1, pp. 60-70, 2009.

[22] S. K. Lam, A. Uduwage, Z. Dong et al., "WP: clubhouse? An exploration of wikipedia's gender imbalance," in Proceedings of the 7th International Symposium on Wikis and Open Collaboration, Mountain View, CA, USA, October 2011.

[23] C. Wagner, D. Garcia, M. Jadidi, and M. Strohmaier, "It's a Man'sWikipedia? Assessing gender inequality in an online encyclopedia," in Proceedings of the 9th International Conference on Web and Social Media, ICWSM 2015, pp. 454-463, Oxford, UK, 2015.

[24] C. Wagner, E. Graells-Garrido, D. Garcia, and F. Menczer, "Women through the glass ceiling: gender asymmetries in Wikipedia," EPJ Data Science, vol. 5, no. 1, 2016.

[25] P. J. February, "Teaching and learning to read in Afrikaans teacher competence," 2018, https://jyx.jyu.fi/handle/ $123456789 / 59086$.

[26] Council of Europe, European Charter for Regional or Minority Languages, Council of Europe, Strasbourg, France, 1998, https://www.coe.int/en/web/conventions/full-list/-/ conventions/treaty/148.

[27] M. D. Integration, Wie Verbreitet Ist Herkunftssprachlicher Unterricht?, Mediendienst Integration, Berlin, Germany, https://mediendienst-integration.de/artikel/wie-verbreitetist-herkunftssprachlicher-unterricht.html, 2020.

[28] J. A. Banks and P. Cookson, G. Gay et al., "Diversity within unity: essential principles for teaching and learning in a multicultural society, Phi Delta Kappan, vol. 83, no. 3, 2001.

[29] C. Newstreet, A. Sarker, and R. Shearer, "Teaching empathy: exploring multiple perspectives to address islamophobia through children's literature," The Reading Teacher, vol. 72, no. 5, pp. 559-568, 2019.

[30] M. W. Gerson and L. Neilson, "The importance of identity development, principled moral reasoning, and empathy as predictors of openness to diversity in emerging adults," SAGE Open, vol. 4, no. 4, 2014.

[31] G. Steiner-Khamsi, "New directions in policy borrowing research," Asia Pacific Education Review, vol. 17, no. 3, pp. 381-390, 2016.

[32] T. Richter and M. McPherson, "Open educational resources: education for the world?" Distance Education, vol. 33, no. 2, pp. 201-219, 2012.

[33] E. Callahan, "Cross-cultural empathy: learning about diverse users in design thinking process," in HCI International 2018-Posters' Extended Abstracts, C. Stephanidis, Ed., pp. 236-240, Springer International Publishing, Cham, Switzerland, 2018. 